\title{
GALICIA, ¿EN LA ORA MARITIMA DE R.F. AVIENO?
}

\author{
Por \\ ANA M ${ }^{a}$ SUÁREZ PIÑEIRO*
}

\section{RESUMEN}

En ocasiones, las fuentes antiguas han sido abordadas con el afán de identificar los lugares y accidentes geográficos que mencionan con los que conocemos en la actualidad. Ello puede conducir a interpretaciones erróneas, como en el caso de la Ora maritima, un texto complejo y lleno de incógnitas atribuido a Rufo Festo Avieno. A continuación planteamos una propuesta de interpretación de los versos que tradicionalmente se vinculan con el territorio del Noroeste peninsular (vv. 90-200).

\section{PALABRAS CLAVE}

Avieno, Ora maritima, Geografía antigua, Oestrymnia, Ophiusa

\section{ABSTRACT}

The classical sources have been some times studied in order to identify names and places with the present Geograghy. This position can produce

\footnotetext{
* Investigadora contrata (I3P) del CSIC.

«CUADERNOS DE ESTUDIOS GALLEGOS», Tomo XLIX, Fascículo 115, Santiago 2002.
} 
mistaken interpretations, as in the case of the Ora maritima, a complicated and dark work attributed to Rufus Festus Avienus. We propose here an interpretation of the verses that have been related to the Northwest of the Iberian Peninsula.

\section{KEYWORDS}

Avienus, Ora maritima, Ancient Geography, Oestrymnia, Ophiusa

1. Durante mucho tiempo, las fuentes antiguas han sido abordadas con el afán de reconocer los lugares que se mencionan identificándolos con los territorios que nos son familiares.

Es decir, se ha tendido a la identificación inmediata de sitios y accidentes geográficos o se ha tratado de buscar en los pueblos citados los ancestros de los pobladores actuales. En ocasiones, este acercamiento puede ser correcto, pero en otras, en cambio, nos conduce a interpretaciones erróneas, fruto más de la influencia de nuestro conocimiento presente que de la información que nos aporta la fuente clásica. Este es, en buena medida, el caso de la obra que aquí nos ocupa, la Ora maritima, atribuida a Rufo Festo Avieno.

En esta obra de 700 versos, Avieno describe las costas del sur de Francia y de la Península Ibérica, al tiempo que alude a pueblos desconocidos (estrimnios, sefes, dráganos). Hay que recordar que los navegantes antiguos realizaban anotaciones de sus viajes aportando información sobre accidentes geográficos costeros, distancias, duración de las rutas, así como sobre los pueblos que visitaban. A partir de aquí surgieron géneros literarios como la periégesis y el periplo. La periégesis incluía descripciones de elementos geográficos de la costa y de las regiones del interior, junto con aspectos de tipo etnográfico o mítico; el periplo, más ligado en su origen a los manuales náuticos, recogía datos relativos a la experiencia práctica del navegante.

La Ora maritima podría contener las referencias más antiguas a estas tierras de occidente (s. VI a. C.). Se trata, en cualquier caso, de un texto complejo, lleno de incógnitas, que ha suscitado un intenso debate historiográfico.

«CUADERNOS DE ESTUDIOS GALLEGOS», Tomo XLIX, Fascículo 115, Santiago 2002. 
2. Tanto la obra como la figura de Avieno siguen abiertas a la polémica y muchos son los interrogantes que permanecen sin respuesta, a pesar de los numerosos estudios que se han realizado al respecto.

Sobre su vida y familia la principal reconstrucción corresponde a J. Matthew ${ }^{1}$. Así, suponemos que sería originario de Volsinii (Etruria) y habría emigrado a Roma con su familia (por ser ésta la mejor vía para la promoción social y política). Sabemos que era de rango senatorial y que viviría en Roma en el s. IV, pudiendo ser considerado un buen ejemplo de senador pagano culto, deseoso de mantener, o mejor aún, de resucitar las viejas tradiciones paganas.

A este autor se le han atribuido de forma errónea algunas obras, pero aquellas que corresponde considerar como propias son: la traducción de los Phaenomena de Arato, la Descriptio Orbis Terrae (equivalente a una traducción libre de la obra de Dionisio Periegeta, del s. II) y la Ora maritima, la más importante para toda aquella información relativa a la Península Ibérica.

Una aportación clave al estudio de la Ora maritima fue el trabajo de A. Schulten ${ }^{2}$, quien dedicó tres años de su vida (1914-1916) a la investigación de la misma. Para ello utilizó mapas costeros de la Península, llegando él mismo a recorrer en barco sus costas. Este autor concluye que, teniendo en cuenta que la Descriptio Orbis Terrae y los Phaenomena son traducciones del griego de autores anteriores, la Ora maritima debe ser, de igual modo, la traducción de alguna obra precedente. Defendió, por tanto, la existencia de un único periplo originario, es decir, un paleoperiplo, idea que, con modificaciones, secundaron otros muchos investigadores ${ }^{3}$. Hay que anotar, sin embargo, que ninguna fuente ni el propio Avieno corroboran esta tesis.

Aun aceptando muchos la teoría de que la Ora maritima tiene su fundamento en algún periplo anterior, surge la polémica a la hora de discer-

${ }^{1}$ «Continuity in Roman family: the Rufi Festi of Volsinii», Historia, 16 (1967), pp. 490-493.

${ }^{2}$ Fontes Hispaniae Antiquae I, Avieno, 'Ora Maritima', 1922 (Barcelona 1955), p. $11 \mathrm{ss}$

${ }^{3}$ M. Ninck: Die Entdeckung von Europa durch die Griechen, Basilea, 1945; J. P. Murphy: Rufus Festus Avienus, Ora maritima, Chicago, 1977; A. Peretti: Il Periplo di Scilae. Studio sul primo portolano del Mediterraneo, Pisa, 1979; J. Ribeiro Ferreiro: Ora Maritima, Coimbra,1985.

«CUADERNOS DE ESTUDIOS GALLEGOS», Tomo XLIX, Fascículo 115, Santiago 2002. 
nir qué obra u obras estarían en su base. Schulten cree que su autor partió de elementos del periplo de Eutímenes de Marsella (s. VI a. C.), del que tampoco conservamos más que contadas referencias. A su juicio, Avieno se habría limitado a traducir al latín a un autor griego, un maestro del s. I. a. C., que, a su vez, se habría servido de fuentes anteriores como el Periplo Marsellés y otros trabajos. Por su parte, M. Schanz ${ }^{4}$ propuso la existencia de dos periplos, uno que abarcaba desde Britania hasta las Columnas de Hércules -siglo II a. C.- y otro, del siglo IV a. C , que describía las costas de Cádiz hacia el este. En este caso, un autor posterior, de época augústea, habría sido el responsable de ensamblar ambos textos. Para A. Blázquez ${ }^{5}$, Avieno habría partido del periplo del cartaginés Himilcón (siglo VI/V a. C.), obra que no ha llegado hasta nosotros.

En contra de la existencia de un paleoperiplo se sitúa el trabajo de A. Berthelot $^{6}$, que alcanza conclusiones muy distintas a las de sus colegas anteriores. Rechaza la idea de que la Ora maritima sea copia de un antiguo periplo al contener datos tanto sobre la costa como sobre el interior. A su juicio se trataría, más bien, de un trabajo fruto de la combinación de gran variedad de fuentes y autores, de épocas diversas ${ }^{7}$, unidos por la mano de Avieno según los gustos arcaizantes de la época. Estas afirmaciones han tenido un gran seguimiento por parte de los investigadores posteriores ${ }^{8}$.

En suma, permanece pues sin resolverse la cuestión de las fuentes aquí empleadas. Si bien muy pocos sostienen ya la tesis de Schulten, sí se reconoce la presencia de datos de indudable antigüedad ${ }^{9}$.

\footnotetext{
${ }^{4}$ Geschichte der römischen Litteratur, IV, München,1959 (1914), pp. 15-16.

${ }^{5}$ Avieno, Ora maritima, Madrid, 1923, passim.

${ }^{6}$ Festus Avienus.Ora Maritima, Paris, 1934.

${ }^{7}$ R. Carpenter (Beyond the Pillars of Heracles, New York, 1973, pp. 200-201) piensa en Piteas (s. IV a. C.) como fuente de Avieno (pp. 199-214); a similares conclusiones cronológicas llega D. Stichtenoth: Rufus Festus Avienus. Ora Maritima, Darmstadt, 1968.

${ }^{8}$ P. Villaba i Varneda (Ruf Fest Aviè. Periple Ora Maritima, Barcelona, 1986) niega la existencia de un paleoperiplo y se inclina por considerar la Ora maritima como una síntesis fruto de la elaboración propia de su autor. Se puede seguir la evolución de esta polémica de forma condensada en J. Mangas y D. Plácido: Testimonia Hispaniae Antiqua. Madrid, 1994, pp. 13-27; así como la bibliografía publicada hasta 1994 (pp. 347-392).

${ }^{9}$ Como es el caso, entre otros muchos, de L. Antonelli: I Greci oltre Gibilterra, Roma, 1997, p. 104.
} 
Ante estas dificultades, en los últimos años el interés de los estudiosos se ha ido encaminando hacia la propia literatura coetánea de Avieno, con el fin de comprender mejor el ambiente cultural del siglo IV. En este sentido, hoy se acentúa la inclinación por resaltar el gusto predominante de la época, arcaizante y proclive a la imitación y a la vuelta a los autores clásicos. Tengamos presente que la recuperación del pasado era entonces la vía más adecuada para alcanzar la renovación del presente: el pasado romano no cristiano se había convertido entonces en un arma ideológica de primera magnitud, así como en un refugio para los sectores de las oligarquías senatoriales paganas.

Por todo ello, en la actualidad existe una tendencia proclive a abordar la cuestión atendiendo, ante todo, a sus conceptos filológicos, buscando la interpretación de la Ora maritima a la luz de la tradición literaria e ideológica de su propio tiempo. González Ponce ${ }^{10}$, por ejemplo, incide en el gusto arcaizante de la obra, presente en nombres de ciudades y pueblos (muestra de qué manera se prefieren formas antiguas, ya en desuso, frente a los nombres coetáneos más conocidos).

En conclusión, los estudios más recientes parecen indicarnos la conveniencia de acercarnos a la figura de Avieno, y a su Ora maritima, partiendo de la base de entenderlo como un escritor del siglo IV, que emplea fuentes diversas para fabricar su composición. Estos planteamientos nos invitan además a desistir de discernir, por su imposibilidad, qué periplo o periplos utiliza en cada momento. Por todo ello, se aconseja leer su obra desde la prudencia y la precaución, huyendo de la tentación, que muchos rechazan ${ }^{11}$, de identificar en cada verso y topónimo la referencia a un lugar reconocible hoy en nuestra realidad geográfica.

${ }^{10}$ F. J. González Ponce: Avieno y el periplo, Écija, 1995. Por su parte, A. Balboa Salgado propone un replanteamiento de las formas del estudio tradicional de la obra, relativizando bastante el valor cartográfico de la misma («Rufo Festo Avieno y su Ora Maritima: Consideraciones acerca de un objeto y un sujeto», Gallaecia 13 (1992), pp. 369-398; La Ora Maritima de Rufo Festo Avieno: Problemas textuales y metodológicos, Santiago, 1997).

${ }^{11}$ Vid., por ejemplo, el trabajo de A. Balboa Salgado: La Ora Maritima de Rufo Festo Avieno..., donde cuestiona la necesidad de buscar correspondencias entre los elementos espaciales citados y la realidad geográfica presente (pp. 11-12).

«CUADERNOS DE ESTUDIOS GALLEGOS», Tomo XLIX, Fascículo 115, Santiago 2002. 
No obstante, por este camino podemos llegar a caer en el riesgo de anular todo valor histórico al poema y reducirlo únicamente a la categoría literaria ${ }^{12}$.

Como veremos muchas son, y en ocasiones muy lejanas, las posibilidades de interpretación de cada accidente geográfico. A pesar de todo, es difícil que el historiador renuncie a intentar buscar aproximaciones a espacios geográficos hoy conocidos e, incluso, se atreva a realizar algunas identificaciones. En algunos casos puede sorprendernos la facilidad con la que cada autor quiere acercar a su propio mundo físico el relato, como una forma de apropiación inconsciente de la fuente. En última instancia, esta postura nos permite analizar otros muchos elementos que acompañan el relato y que tienen un indudable valor histórico, cuyo estudio debemos afrontar. Aun siendo conscientes del riesgo y de los errores que entraña, algunos trabajos de recopilación y estudio de fuentes antiguas, publicados en los últimos años, han intentado eludir los aspectos más controvertidos del tema con fortuna desigual ${ }^{13}$.

A continuación recogemos una propuesta de lectura de los versos que podrían hacer referencia al territorio del noroeste peninsular (vv. 90-200) y sus posibles interpretaciones ${ }^{14}$.

3. El texto alude con gran imprecisión a las tierras Estrímnicas (vv. 90-98) lo que ha dificultado en extremo la identificación de sus parajes. Por esta razón no es de extrañar que, según el autor o la corriente historiográfica, se hayan situado en Galicia, la región de Bretaña, las Is-

\footnotetext{
${ }^{12}$ Como parecen preferir F. J. González Ponce (Avieno y el periplo...) o P. Villalba i Varneda (Ruf Fest Aviè. Periple...). También F. J. Gómez Espelosín reconoce recientemente la escasa utilidad de la obra en cuanto a su valor geográfico ya que, en su opinión, los datos que contiene se han ido convirtiendo con el paso del tiempo en tópicos, ajenos a la realidad y, en algunos casos, en meros recursos retóricos o literarios ( $E l$ descubrimiento del mundo. Geografia y viajeros en la Antigua Grecia, Madrid, 2000, pp. 110-115).

${ }^{13}$ Como las publicaciones de la T.I.R. o la reedición de las Fontes Hispaniae Antiquae de Schulten en el proyecto de Testimonia Hispaniae Antiqua, dedicado en su primer volumen a la obra de Avieno.

${ }^{14}$ De forma general se puede seguir el trabajo de J. Mangas y D. Plácido: Testimonia..., en cuya redacción colaboramos.
} 
las Británicas, o incluso, en una interpretación mucho más meridional, en tierras andaluzas ${ }^{15}$.

En su momento halló un amplio seguimiento la tendencia de identificar los párrafos referidos a la Oestrymnia y a Ophiusa con el territorio de Galicia. Esta práctica fue seguida, ante todo, por autores gallegos ${ }^{16}$, siendo quizá López Cuevillas uno de sus máximos defensores ${ }^{17}$.

También existen investigadores que se inclinan por Bretaña y las Islas Británicas ${ }^{18}$. Entre los más destacados se encuentran K. Müllenhoff ${ }^{19}$ y A. Schulten. Para ellos, el cabo Oestrymnis (v. 91) correspondería al Ouessant, la Punta de S. Mathieu, el cabo Penmarch o la Punta de Raz, según los autores; el golfo Estrímnico (v. 95) se hallaría en la zona situada entre Brest y Douarnenez; las islas Estrímnidas (v. 96) se corresponderían con las pequeñas islas del este de Ouessant o del suroeste de Gran Bretaña ${ }^{20}$; la isla Sagrada (v. 108) parece ser Irlanda, habitada por los Hibernos y, finalmente, la isla de los Albiones (v. 112) se identificaría con Gran Bretaña.

${ }^{15} \mathrm{La}$ indefinición de los datos ha llevado a diferentes autores a ubicar esta descripción en la costa andaluza: A. Blázquez y Delgado Aguilera: El periplo de Himilco, Madrid, 1909; y, posteriormente, F. Wattenberg: «Saltés, la isla de la Atlántida y Tartessos», B. S. A. A. 32 (1966), pp. 125-205.

${ }^{16}$ Sirvan como muestra estas palabras de M. Murguía: «Así lo expresa Festo Avieno, si por las islas y tierras Oestrymnicas, se ha de entender como quieren algunos la región gallega, y como parece desprenderse de aquel interesante, pero obscuro texto, cuyas indicaciones no permiten dudar un momento que el poeta geógrafo se refería en esta ocasión a nuestro país» (Historia de Galicia, La Coruña, 1901, p. 524). «Aparte de ciertas inexactitudes o exageraciones, propias de la poesía, siquiera sean didácticas, no se puede dudar que el poeta latino refirió a Galicia y sus gentes, cuando habló de las Oestrynindas» (ibidem, p. 548). Y fuera de Galicia, podemos señalar a F. Martins Sarmento: Rufo Festo Avieno, Ora Maritima, Oporto, 1880.

${ }^{17}$ F. López Cuevillas: Os Oestrimnios, os Saefes e a Ofiolatría en Galicia, Aquivo do Seminario de Estudos Galegos 2, 1929 (reed. 1992); «Estudos sobre a edade do ferro no N. O. peninsular. As fontes literarias», Arquivo do Seminario de Estudios Galegos 6, o La civilización céltica en Galicia, Santiago, 1953 (reed. 1989).

${ }^{18}$ Con apreciaciones particulares: A. Schulten: Avieno, Ora Maritima ...; A. Berthelot: Ora maritima...; J. P. Murphy: Avieno. Ora Maritima. Or description...; J. Ribeiro Ferreira: Ora Maritima,...

${ }^{19}$ Deutsche Althunskunde I, Berlín, 1870.

${ }^{20} \mathrm{La}$ dificultad de estos términos lleva a la T.I.R. a renunciar a su ubicación (las Oestrymnides insulae son catalogadas como de «localización desconocida», p. 80).

«CUADERNOS DE ESTUDIOS GALLEGOS», Tomo XLIX, Fascículo 115, Santiago 2002. 
Los habitantes de la región emplean unos barcos de piel (v. 106) que aparecerán también mencionados en otras fuentes ${ }^{21}$. Estas embarcaciones utilizaban como armazón un entramado de mimbre que revestían, en su parte externa, con pieles cosidas para evitar el paso del agua. La flexibilidad del material dotaría a estas naves de una gran capacidad de adaptación al mar, necesaria para surcar el océano ${ }^{22}$.

El dato de que tartesios y gaditanos comerciaban en los límites de las Estrímnidas (v. 113-116) no supone ninguna ayuda a la hora de determinar el emplazamiento concreto de estas tierras. La presencia de estaño o la existencia de contactos comerciales con el mundo tartésico no es exclusiva de ninguna de las regiones apuntadas. El esquema comercial de Tartesos incluía en sus viajes de intercambio o aprovisionamiento no sólo el litoral gallego, sino también las costas de Bretaña.

Tras anotar la situación del Golfo de Vizcaya (golfo de Ofiusa, vv. 147-148), el relato parece adentrarse definitivamente en tierras hispanas.

Por Ofiusa (v. 152), del griego ő $\phi \iota \varsigma$, literalmente 'tierra de serpientes', se entiende el conjunto de Hispania. Esta designación, dada probablemente por los masaliotas, engloba el territorio que sigue inmediatamente al Golfo de Vizcaya y, por extensión, a su parte septentrional y occidental. Ofiusa fue llamada también Oestrymnis (v. 154), denominación anterior a las fuentes griegas, que recoge, posiblemente, noticias de origen cartaginés.

Allí habitaban los Estrímnicos (v. 155) quienes, al parecer, serían los pueblos megalíticos artífices de la cultura del Bronce Atlántico en el Noroeste (con estrechas vinculaciones con Irlanda y Gran Bretaña), supuestamente expulsados o sometidos por grupos celtas. Este pasaje, en el que se refiere cómo los Estrímnicos fueron expulsados por una multitud de serpientes (vv. 155-157), ha sido objeto de interpretaciones muy curiosas y discutibles ${ }^{23}$.

${ }^{21}$ Estrabón 3, 3, 7 (sobre barcos de cuero en el norte de la Península Ibérica) y, de forma general, Plinio: Naturalis Historia 7, 56; 14, 16; 34, 156-158; César: Bellum Civile 1, 54; Virgilio: Eneida 9, 87.

${ }^{22}$ Vid. al respecto J. Alvar Ezquerra: La navegación prerromana en la Península Ibérica; colonizadores e indigenas, Madrid, 1981, pp. 228-229.

${ }^{23}$ Seguimos la revisión del pasaje planteada por J. C. Bemejo Barrera, «Un país devastado por la plaga», en J. C. Bermejo (ed.) Mitología y mitos de la Hispania prerromana 2, Madrid, 1986, pp. 57-75. De igual modo lo interpreta A. Balboa Salgado: La Ora Maritima de Rufo Festo..., pp. 24-25. 
Schulten, ante la imposibilidad de admitir una invasión real de serpientes, asoció en su día el término griego $\sigma \eta \pi \epsilon \varsigma$ (serpiente) con el grupo de población de los sefes ${ }^{24}$. Se narraría entonces, según dicho autor, la invasión de un pueblo celta que en su desplazamiento habría expulsado al grupo de los Estrímnicos. Esta solución fue asumida ampliamente y completada, entre otros, por López Cuevillas y Bouza Brey, quienes hicieron de la serpiente el animal totémico del pueblo invasor. Estos autores utilizaron como argumento la pervivencia de dicho culto en el folklore contemporáneo de la serpiente en Galicia ${ }^{25}$.

No obstante, hoy se cree que la interpretación del texto pasa por comprender su naturaleza mítica. En este sentido, en diferentes culturas se reconoce el tema mítico, de carácter apocalíptico, de plagas de animales que asolan territorios remotos. Este mito se encuentra en la propia historiografía griega: la mitología helénica situaba a monstruos serpentiformes en parajes alejados de la civilización. La construcción mitológica permite afrontar la descripción de una región prácticamente desconocida, como a la que aquí nos traslada Avieno, y que se imagina, por esa razón, plagada de animales fantásticos o nocivos, como las serpientes.

Continúa el relato con la descripción geográfica de la orla marítima de norte a sur. El litoral es descrito, de forma detallada, respondiendo a las anotaciones que podría haber hecho un navegante en una singladura por la costa.

El cabo Arvio (v. 160) ${ }^{26}$ se identifica con el cabo Ortegal, el extremo más occidental de la costa norte de la Península, y, justamente por ello, de referencia casi obligada en las fuentes ${ }^{27}$. Para L. Monteagudo se trataría exactamente de la Punta dos Aguillóns ${ }^{28}$.

\footnotetext{
${ }^{24}$ A. Schulten: Avieno, 'Ora Maritima'..., p. 90.

${ }^{25}$ F. López Cuevillas y F. Bouza Brey: «Os Oestrimnios, os saefes e a ofiolatría na Galiza»..., pp. 29-193. Carece de fundamento establecer relaciones entre las formas míticas de serpientes, supuestamente vinculadas a antiguas culturas del N. O., con las formas míticas que adoptan en la actualidad en el folklore gallego. Los mitos asociados con ciertos restos arqueológicos de la Antigüedad sólo nos ilustran, como tales, sobre la propia sociedad que los cuenta, pero no sobre aquella que construyó el objeto que sirve de soporte al mito. Vid. F. Criado Boado: «Serpientes gallegas; madres contra rameras», en J. C. Bermejo Barrera (ed.): Mitología y mitos.... 2, pp. 241-274.

${ }^{26}$ Ptolomeo: Geog. 2, 6, 4.

${ }^{27}$ Tabula Imperii Romani. (Hoja K-29: Porto), 1991, p. 64.

28 «Carta de Coruña romana», Emerita 25 (1957), pp. 64-72. No obstante, como ocurre al abordar otros puntos geográficos de la Ora maritima, se han apuntado otras
} 
Entrando en el litoral portugués, la isla consagrada a Saturno (v. 165) correspondería a la isla Berlenga, ubicada frente al cabo Carboeiro. El periplo parece referirse al oleaje intenso que azotaba la isla, al estar rodeada de escollos (vv. 160-170) ${ }^{29}$.

El cabo de Ofiusa (vv. 171-172) se identifica con el cabo de Roca, punto más occidental de toda la Península ${ }^{30}$, que antecede al estuario del Tajo. Se detiene Avieno en la descripción del estuario, el golfo de Lisboa (vv. 174-177), muy abierto, al que el navegante accede beneficiándose primero del viento norte y después del sur ${ }^{31}$.

A continuación, se halla el cabo Ceprésico, o Cémpsico (vv. 182-183),

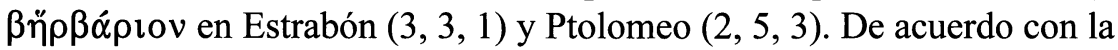
lectura geográfica que estamos siguiendo, coincidiría con el actual cabo Espichel $^{32}$.

La isla Acale (vv. 183-184) se encuentra hoy en día incluida en la península de Tróia. Avieno relataría el fenómeno que produce el río Sado al desembocar en el mar, enturbiando con su limo las aguas (vv. 184-194) ${ }^{33}$.

Parece que aquí se da por finalizado el territorio de Ofiusa, ya que se procede a enumerar los pueblos que la habitan. La narración abandona por ello la costa y se adentra en el interior. Se mencionan pueblos cuyos nombres no volverán a aparecer en las fuentes y cuya localización e identificación, muy problemáticas, han abordado numerosos filólogos y arqueólogos ${ }^{34}$.

hipótesis que sitúan el cabo en una posición más meridional: la desembocadura del Miño (Martins Sarmento: Rufo Festo Avieno, Ora Maritima..., p. 42), el cabo Silleiro, en la entrada de la ría de Vigo (Berthelot: Festus Avienus. Ora Maritima..., p. 67) o la desembocadura del río Vouga (J. Alvar: «El comercio del estaño atlántico durante el período orientalizante», Memorias de Historia Antigua 4 (1980), p. 46).

${ }^{29}$ A. Schulten, Avieno, 'Ora Maritima'..., p. 91.

${ }^{30}$ Ibidem, p. 91.

${ }^{31}$ Ibidem, p. 92.

${ }^{32}$ Ibidem, p. 93.

${ }^{33} \mathrm{El}$ estuario del Tajo sufrió una profunda transformación morfológica debido a la acumulación de sedimentos de origen fluvial, depositados a lo largo del tiempo, que provocaron la anexión de muchas de sus islas a tierra firme. Vid. E. Prescott Vicente: «A foz do Sado e os territórios dos Cinetas e dos Cempsos no poema Ora Maritima de Avieno», Boletim do Centro de Estudos do Museu Arqueológico de Sesimbra 5 (1967), p. 68.

${ }^{34} \mathrm{La}$ interpretación del poema ha de ser en este punto, al igual que al tratar de los Estrímnicos, muy cautelosa, rechazando anteriores intentos de ver en el texto una guía literal para conocer a los antiguos pobladores del N. O. peninsular. Vid. de forma orientativa, A. J. Orrio: «Los celtas en el Noroeste», en Los celtas en la Península Ibérica. Revista de Arqueología, Madrid, 1991, pp. 26-35.

«CUADERNOS DE ESTUDIOS GALLEGOS», Tomo XLIX, Fascículo 115, Santiago 2002. 
Los cempsos ${ }^{35}$ y sefes (v. 195) podrían definirse como tribus indoeuropeas, introductoras de la metalurgia del hierro, asentadas desde el s. VI a. C. en los valles del Duero y Tajo (sefes) y en el Alto Alentejo (cempsos). Se trata de grupos que dejarán sentir su influencia sobre el sustrato cultural anterior, perteneciente a la Edad del Bronce.

En la expresión 'rápido luso' (pernix lucis, v. 196) se puede rastrear una referencia, en su caso sería la más antigua, a los antepasados de los lusitanos, que habrían ocupado el territorio situado al norte del Tajo y la cuenca inferior del Duero ${ }^{36}$. Estrabón $(3,3,6)$ quizá confirme esta identifícación ${ }^{37}$.

A la prole de los dráganos (v. 197) ${ }^{38}$, prácticamente desconocida, podríamos calificarla como tribu precelta, que ocuparía la región septentrional de la Península ${ }^{39}$, asiento posteriormente de astures, cántabros y galaicos.

El relato retoma la línea costera alcanzando la isla de Petanion (v. 199), situada en las proximidades de la orilla norte del estuario del río Sado. En la actualidad se halla integrada en la península de Sta. Catarina, ubicada frente a la ciudad de Setúbal, debido a un fenómeno de deposición de arenas fluviales ${ }^{40}$. Aceptando esta localización, el 'puerto ex-

35 Dionisio Periegeta v. 393.

${ }^{36}$ La lectura original, que aquí se mantiene, pernix lucis, fue alterada por Shrader, quien prefirió la fórmula pernix ligus. Ello dio lugar a la aparición de una teoría sobre la presencia ligur en el poblamiento peninsular (A. Schulten: Avieno, 'Ora Maritima'..., p. 94, entre otros autores), hoy completamente desechada. En contra de esta lectura reaccionó en su día Berthelot (Festus Avienus. Ora Maritima..., p. 70) y, con posterioridad P. Vilalba y Varneda: «El text crític de l'Ora Marítima d'Avie», Faventia 7/1 (1983), p. 39.

${ }^{37}$ Estrabón $(3,3,6)$ coincide a la hora de caracterizar a los lusitanos como ágiles

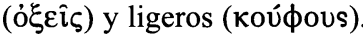

${ }^{38}$ El nombre podría tener también relación con el mundo mítico de la serpiente,

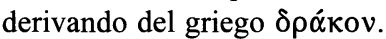

${ }^{39}$ La falta de datos sobre este grupo lleva a Schulten (Avieno, 'Ora Maritima'..., p. 94) a calificarlo de pueblo ligur, o a la consideración de tribu imaginaria por parte de Berthelot.

${ }^{40} \mathrm{La}$ descripción geográfica de dicho estuario no correspondería exactamente con su aspecto actual; habría que tener presente la evolución morfológica sufrida por el mismo (E. Prescott Vicente: «A foz do Sado e os territórios dos Cinetas..., p. 69). También se ha apuntado una identificación más meridional para la isla de Petanion: la isla de Pessegueiro (Alentejo, $15 \mathrm{~km}$. al sur de Sines); vid. C. Tavares da Silva: «Escavações arqueológicas na ilha do Pessegueiro», Al-Madan 2 (1983-84), pp. 20-22.

«CUADERNOS DE ESTUDIOS GALLEGOS», Tomo XLIX, Fascículo 115, Santiago 2002. 
tenso' (patalus portus, v. 200) coincidiría con la desembocadura del río Sado.

4. Texto y traducción ${ }^{41}$

Ora maritima, vv. 90-200

90 Et prominentis hic iugi surgit caput

-Oestrymnin istud dixit aeuum antiquius-, molesque celsa saxei fastigii tota in tepentem maxime uergit notum. Sub huius autem prominentis uertice

95 sinus dehiscit incolis Oestrymnicus, in quo insulae sese exerunt Oestrymnides, laxe iacentes, et metallo diuites stanni atque plumbi. Multa uis hic gentis est, superbus animus, efficax sollertia,

100 negotiandi cura iugis omnibus. Notisque cumbis turbidum late fretum, et beluosi gurgitem Oceani secant. Non hi carinas quippe pinu texere facere morem, non abiete, ut usus est,

105 curuant faselos, sed rei ad miraculum nauigia iunctis semper aptant pellibus, corioque uastum saepe percurrunt salum. Ast hinc duobus in Sacram -sic insulam dixere prisci- solibus cursus rati est.

110 Haec inter undas multam caespitem iacet, eamque late gens Hiernorum colit.

Propinqua rursus insula Albionum patet. Tartesiisque in terminos Oestrymnidum negotiandi mos erat. Carthaginis 
115 etiam coloni et ulgus, inter Herculis agitans columnas, haec adibant aequora.

Quae Himilco Poenus mensibus uix quattuor, ut ipse semet rem probasse retulit enauigantem, posse transmitti adserit.

120 Sic nulla late flabra propellunt ratem, sic regnis humor aequoris pigri stupet. Adiicient illud, plurimum inter gurgites extare fucum, et saepe uirgulti uice retinere pupim. Dicit hic nihilo minus, 125 non in profundum terga dimitti maris, paruoque aquarum uix supertexi solum, obire semper huc et huc ponti feras, nauigia lenta et languide repentia internatare beluas. Si quis dehinc

130 ab insulis Oestrymnicis lembum audeat urgere in undas, axe qua Lycaonis rigescit aethra, caespitem Ligurum subit cassum incolarum, nanque Celtarum manu, crebisque dudum praeliis uacuata sunt.

135 Liguresque pulsi, ut saepe fors aliquos agit, uenere in ista, quae per horrentis tenent plerunque dumos; creber his scrupus locis, rigidaeque rupes, atque montium minae coelo inseruntur. Et fugax gens haec quidem

140 diu inter arta cautium duxit diem, secreta ab undis; nam sali metuens erat priscum ob periculum. Post quies et otium, securitate roborante audaciam, persuasit altis deuehi cubilibus

145 atque in marinos iamlocos descendere. Post illa rursum, qua super fati sumus, magnus patescit aequoris fusi sinus Ophiusam ad usque. Rursum ab huius litore internum ad aequor, qua mare insinuare se، 150 dixi ante terris, quodque Sardum nuncupant, septem dierum tenditur reditu uiae. 
Ophiussa porro tanta panditur latus, quantam iacere Pelopis audis insulam, Graiorum in agro. Haec dicta primo Oestrymnis,

155 locos et arua Oestrymnicis habitantibus; post multa serpens effugauit incolas, uacuamque glaebam nominis fecit sui. Procedit inde in gurgitis Veneris iugum, circumlatratque pontus insulas duas tenue ob locorum inhospitas. Aruium rursum tumescit prominens in asperum Septentrionem. Cursus autem hinc classibus usque in columnas efficacis Herculis quinque est dierum. Post pelagia est insula

165 herbarum abundans atque Saturno sacra. Sed uis in illa tanta naturalis est, ut, si quis hanc innauigando accesserit, mox excitetur propter insulam mare, quatiatur ipsa, et omne subsiliat solum

170 alte intremescens, cetero ad stagni uicem pelago silente. Preminens surgit dehinc Ophiussae in oras, abque Aruii iugo in haec locorum bidui cursus patet. At qui dehiscit inde prolixe sinus,

175 non totus uno facile nauigabilis uento recedit: nunquam medium aderis Zephyro uehente, reliqua deposcunt Notum. Et rursus inde si petat quisquam pede Tartessiorum litus, exsuperet uiam

180 uix luce quarta. Si quis ad Nostrum Mare Malacaeque portum semitam tetenderit, in quinque soles est iter. Tum Cepresicum iugum intumescit. Subiacet porro insula Achale uocata ab incolis. Agrestis fides

185 narrationis prae rei miraculo, sed quam frequens auctoritas sat fulciat. Aiunt in huius insulae confiniis nunquam esse formam gurgiti reliquo parem, 
splendorem ubique quippe inesse fluctibus uitri ad nitorem, et per profundum marmoris cyaneam in undis esse certum imaginem est. Confundi at illic aequor inmundo luto, memorant uetusti, semper atque sordidus ut faeculentos gurgites haerescere.

195 Cempsi atque Saefes arduos collis habent Ophiussae in agro. Propter hos pernix Lucis Draganumque proles sub niuoso maxime septentrione conlocauerant larem.

Poetanion autem est insula ad Saefumum, latet patalusque portus...

90 Y aquí surge la cumbre de un cabo prominente -la Antigüedad más remota lo llamó Estrimnis-, y la mole excelsa de su pedregosa cima se dirige toda entera hacia el cálido Noto. Pero, al pie del vértice de este cabo, se

95 abre a sus habitantes el golfo Estrímnico, en el que surgieron las islas Estrímnidas, extendidas en una vasta amplitud y ricas en metal de estaño y plomo.

Aquí está el gran poder de un pueblo, un espíritu altivo, una destreza eficaz: a todos les posee un

100 constante afán por negociar. Y, en esquifes, surcan, a grandes distancias, el mar zarandeado por los vientos Notos y el abismo del Oceáno, poblado por montruos. En efecto, no suelen ensamblar sus naves con madera de pino, no curvan sus chalupas con la de abeto, como es costumbre, sino que, ¡hecho fantástico!, construyen

105 siempre sus embarcaciones con pieles cosidas, y muchas son las veces que recorren el vasto mar sobre el cuero. Desde aquí, sin embargo, hasta la isla Sagrada -así llamaron la isla los antiguos-, una nave emplea una 110 singladura de dos soles. La isla, en medio del oleaje, se extiende con una gran superficie de tierra, y el pueblo de los hiernos la habita ampliamente.

Cercana aparece, a la vuelta, la isla de los albiones. 
También los tartesios acostumbraban a comerciar hasta los

115 límites de las Estrímnidas. También colonos de Cartago y el pueblo establecido alrededor de la columnas de Hércules llegaban hasta estos mares.

El cartaginés Himilcón asegura que estos mares apenas se pueden atravesar en cuatro meses, tal como él mismo contó

120 que lo había comprobado navegando personalmente. Así, ningún viento empuja la nave a una gran distancia; asimismo el agua del mar perezoso no se mueve en sus dominios. Se añadirá a esto el hecho de que sobresale, en medio de las aguas marinas, gran cantidad de algas, y de que, la mayoría de las veces, retiene la popa al formar

125 grandes malezas. Dice él, nada menos, que aquí las espaldas del mar no se hunden en la profundidad y que el fondo apenas queda cubierto por un palmo de agua, que las fieras marinas circulan de un lado para otro, que unos monstruos nadan por entre las naves mientras avanzan lentas y sin fuerza.

130 Si alguien, desde aquí, desde las islas Estrímnidas, se atreve a impeler su nave hacia las olas por el eje de la hija de Licaón, en donde el aire se hiela, llega a la tierra de los ligures, vacía de habitantes, pues hace tiempo que aquellas regiones han sido despobladas por los

135 celtas y por guerras continuas. Y los ligures expulsados, tal como la suerte a menudo trata a algunos, llegaron a los lugares actuales, que pueblan, la mayoría de las veces, en medio de tremendos zarzales. En estos parajes hay mucha piedra y rocas abruptas, y las cumbres de las montañas se clavan amenazadoras en el cielo. Y

140 este pueblo fugitivo vivió -verdaderamente un largo tiempo- entre abismos pedregosos, alejado de las aguas marinas, pues temía el mar en recuerdo del peligro sufrido antiguamente. Después, la tranquilidad y el ocio, mientras la seguridad fortalecía su audacia, lo convencieron para salir de sus cobijos encumbrados y 145 bajar ya hacia los parajes marinos.

Después de aquellas regiones que más arriba he contado, 
se abre, en sentido contrario, un vasto golfo de amplio mar hasta Ofiusa. Desde su litoral, en sentido inverso, hasta el Mar Interior, allá por donde he dicho antes que

150 el mar se engolfa en nuestras tierras, y que llaman Mar Sardo, hay de retorno una distancia de un camino de siete días. Ofiusa se proyecta tanto hacia delante con sus costas como oyes decir que las isla de Pélope se alarga en el territorio griego. Fue llamada, al principio, Estrimnis,

155 porque los estrímnicos poblaban sus parajes y cabos; después, una multitud de serpientes hizo huir a sus habitantes y dejó el territorio privado de su nombre. Avanza, a continuación, en dirección a los abismos marinos, el cabo de Venus, y el mar ladra alrededor de

160 dos islas despobladas por la estrechez de sus parajes. Después, el cabo Arvio se eleva altivo hacia el septentrión desapacible; desde aquí, pues, hasta las columnas de Hércules victorioso, los navíos tienen una singladura de cinco días.

165 A continuación, hay una isla en alta mar, rica en plantas y consagrada a Saturno. Pero la fuerza de su naturaleza es tan potente, que, si se le acerca algún navegante, inmediatamente el mar de alrededor de las isla se excita,

170 la isla misma se conmueve, y todo su suelo salta estremeciéndose desde sus profundidades, mientras el resto del piélago permance silencioso como un lago. Después, surge un cabo dirigido hacia las costas de Ofiusa, y desde el cabo de Arvio hasta estos parajes hay un recorrido practicable en dos días. El golfo, sin embargo, que desde allí se abre en una gran extensión, no es todo él fácilmente navegable

175 con un solo viento: nunca conseguirás sobrepasar la mitad con el soplo del Céfiro; las millas restantes exigen el Noto. Y si alguien, desde allí, retorna a pie al litoral de los tartesios, apenas habrá 180 recorrido el camino al cuarto día; si alguien intentara la ruta hacia el Mar Nuestro y el puerto de Malaca, el camino sería factible en cinco soles. 
A continuación, se levanta altivo el cabo Ceprésico. Más adelante, yace la isla que sus habitantes llaman Acale. Es difícil creer lo que se cuenta de allí por

185 el carácter maravilloso del hecho, pero abundantes testimonios lo apoyan suficientemente. Se dice que el aspecto del mar, en los confines de esta isla, nunca es igual al del resto -pues por doquier el esplendor penetra en las aguas como si de la nitidez del vidrio se tratara, y es cierto que, por la profundidad del

190 mar, las olas tienen una transparencia azulada-, sino que la superficie marina está, allí, mezclada con lodo inmundo, según recuerdan los antiguos, y que la masa líquida está siempre pegajosa por su suciedad, como si de heces se tratara.

195 Los cempsos y los sefes ocupan las abruptas colinas del teritorio de Ofiusa. Cerca de ellos se establecieron el rápido luso y la prole de los dráganos, en dirección hacia el septentrión de abundantes nieves. 